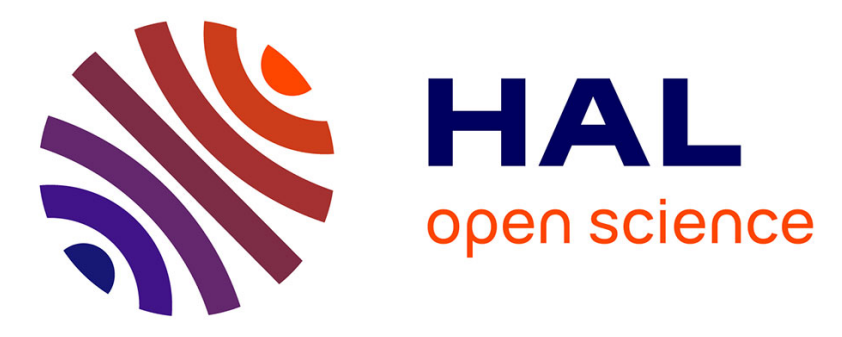

\title{
Assessments of Material Models Through Simple Machining Tests
}

Francisco Chinesta, Luigino Filice, Fabrizio Micari, Stefania Rizzuti, Domenico Umbrello

\section{- To cite this version:}

Francisco Chinesta, Luigino Filice, Fabrizio Micari, Stefania Rizzuti, Domenico Umbrello. Assessments of Material Models Through Simple Machining Tests. 11th ESAFORM Conference on Material Forming, 2008, Lyon, France. pp.507-510, 10.1007/s12289-008-0171-4 . hal-00289839

\section{HAL Id: hal-00289839 \\ https://hal.science/hal-00289839}

Submitted on 28 Oct 2021

HAL is a multi-disciplinary open access archive for the deposit and dissemination of scientific research documents, whether they are published or not. The documents may come from teaching and research institutions in France or abroad, or from public or private research centers.
L'archive ouverte pluridisciplinaire HAL, est destinée au dépôt et à la diffusion de documents scientifiques de niveau recherche, publiés ou non, émanant des établissements d'enseignement et de recherche français ou étrangers, des laboratoires publics ou privés.

\section{(c)(1)}

Distributed under a Creative Commons Attribution| 4.0 International License 


\title{
Assessment of material models through simple machining tests
}

\author{
F. Chinesta ${ }^{1}$, L. Filice ${ }^{2}$, F. Micari ${ }^{3}$, S. Rizzuti ${ }^{2}$, D. Umbrello ${ }^{2}$ \\ ${ }^{1}$ LMSP UMR 8106 CNRS-ENSAM-ESEM - F75013, 151 Boulevard de l'Hopital, Paris - France \\ URL: www.ensam.fr \\ e-mail: francisco.chinesta@paris.ensam.fr \\ ${ }^{2}$ Dept. of Mechanical Engineering, University of Calabria - 87036, Rende - Italy \\ URL: $\underline{w w w . u n i c a l . i t}$ \\ e-mail: l.filice@unical.it; stefania.rizzuti@unical.it

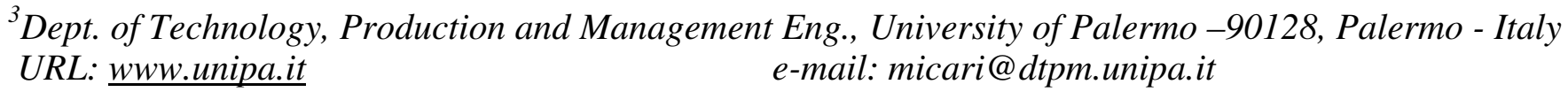

\begin{abstract}
The accuracy of the results obtained from FEM simulation of machining operations depends on the accuracy of input data. Among these, the flow stress data of the workpiece are extremely important together with the friction along the tool-chip interface. In this study, an identification procedure for the determination of material parameters that are used for the FEM simulation of machining processes is proposed. The procedure is based on the coupling of a numerical identification procedure and Arbitrarian Lagrangian Eulerian (ALE) Finite Element simulations of turning operations. An experimental campaign was developed in order to calibrate the model and to validate the procedure. The basic idea is to utilize only machining tests to properly define the material behaviour of the workpiece material, taking also into account the thermal phenomena involved in the process. The preliminary results of this analysis are discussed in the paper.
\end{abstract}

Key words: Material modelling, Inverse Approach, Machining, Finite Element Simulation

\section{INTRODUCTION}

Finite Element Method (FEM) based simulation is a very useful tool for obtaining relevant information in machining; the latter a usually difficult to experimentally acquire. Some examples are strain, strain rate, stress and temperature in both tool and machined workpiece. Anyway, the reliability of the results obtained from FEM simulation depends on the accuracy of the input values. For these reasons, numerical simulation of cutting process is still a very hard challenge since a lot of staffs have to be taken into account. Although sometimes a strong geometrical simplification is done studying orthogonal cutting conditions (thus reducing the computational complexity), other aspects must be properly modelled in order to supply reliable result as simulation output. Among them, material behaviour, friction, energy conversion into heat and its propagation, definition of material damage criteria are just few examples that engage a number of scientists all over the World. Actually, material behaviour modelling is usually regarded as a known issue since several laws are easily recognizable in literature [1-4], almost for the most diffused materials. On the other hand, comparing the different laws, it is possible to recognize also relevant discrepancies that suggest to investigate more deeply in that direction [5]. Traditionally the studies were mainly oriented toward friction modelling [6], damage criteria development [7], extension to 3D geometries but, nevertheless these huge efforts, some results are today still unsatisfactory. For instance, it is well known in the cutting community that the simple ratio between cutting and thrust force is not accurately calculated. At the same time, the thermal field is usually not well calculated, especially using Lagrangian formulation. This relevant inaccuracy may be due, also, to the material behaviour laws which are usually obtained by processes completely different respect to cutting. In fact, how it is well-known, to be useful in metal cutting simulation, flow stress data must be obtained at high strain rates (up to $10^{6}$ $\mathrm{s}^{-1}$ ), temperatures (up to $1000^{\circ} \mathrm{C}$ ) and strain (up to 
4). These data are impossible to reliably obtain with conventional tensile and compression tests. Often high speed Hopkinson's bar compression tests are used but these tests require much effort and expensive equipment, and can provide data only for limited strain rates (up to $10^{4} \mathrm{~s}^{-1}$ ) and strain (up to 1.0 or less). Taking into account all these considerations, a new strategy is proposed in this work, based on the use of some simple measures obtained during cutting process, i.e. cutting force, thrust force and temperature in the tool. In this preliminary approach, for sake of simplicity, the problem was decomposed taking into account the reduced sensitivity of some variables on the material law. The latter was then obtained by an inverse approach using the results of a Lagrangian-Eulerian simulation and utilizing an optimization algorithm. The validity of the simplified material law was determined and its validity was verified in other cases. A satisfactory agreement between experimental and numerical data was found. The results will be presented in the following.

\section{THE PROPOSED PROCEDURE}

\subsection{Experimental tests}

As above introduced, an experimental investigation was preliminarily carried out in order to acquire reliable data to develop the procedure and to set-up the material model. In particular, cutting processes were run on a lathe, reproducing orthogonal cutting conditions (Figure 1).

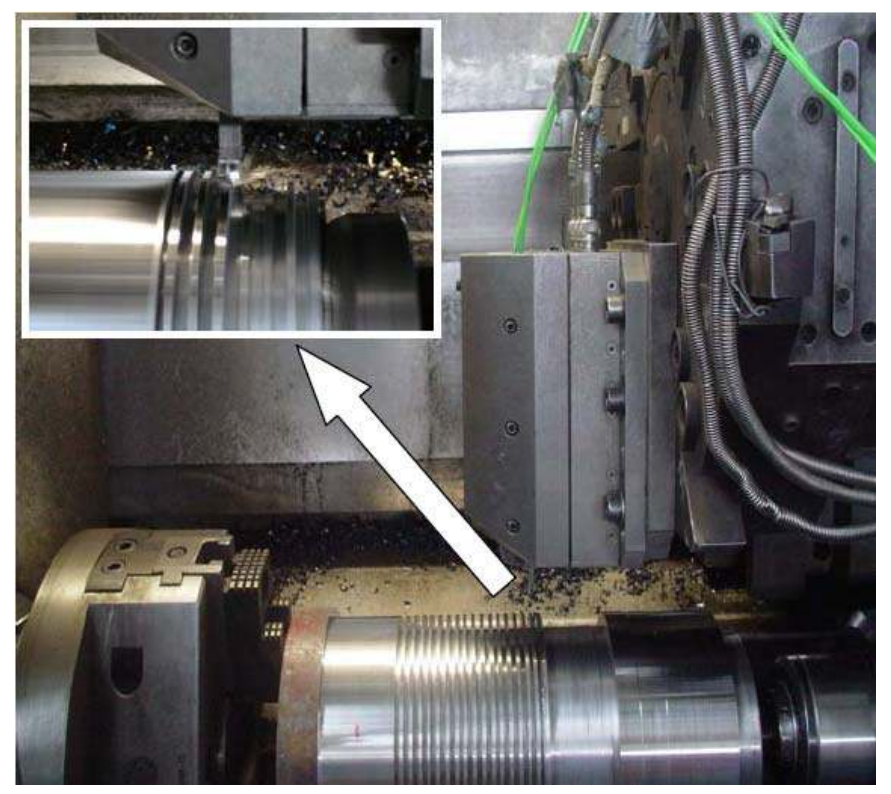

Fig. 1.The experimental set-up.
The workpiece material was an AISI 1045 steel, while the cutting tool was an uncoated carbide ISO P30, with a rake angle of $0^{\circ}$ and a relief angle of $6^{\circ}$. The tests were executed without any lubricant at the tool-chip interface, with the values of cutting speed and feed rate reported in Table 1.

Table 1. Cutting conditions

\begin{tabular}{lccc}
\hline Test case & 1 & 2 & 3 \\
\hline Cutting speed $\mathrm{V}_{\mathrm{c}}[\mathrm{m} / \mathrm{min}]$ & 100 & 150 & 100 \\
\hline Feed f $[\mathrm{mm} / \mathrm{rev}]$ & 0.1 & 0.1 & 0.15 \\
\hline
\end{tabular}

During the tests cutting and thrust forces were measured by using a piezoelectric dynamometer while an optical microscope was used to estimate the chip thickness. The temperature was measured using an embedded thermocouple, close to the cutting edge, at a distance of $0.6 \mathrm{~mm}$ from the rake face and $0.35 \mathrm{~mm}$ from the tool tip (Figure 2).

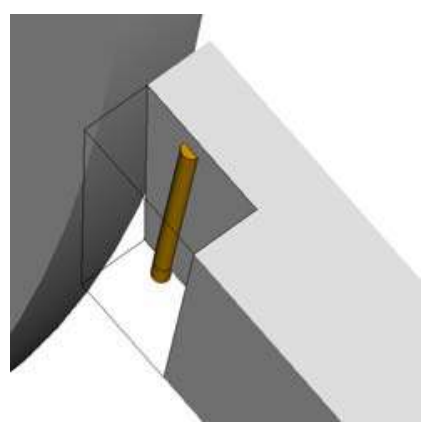

Fig. 2. Thermocouple position

Table 2 shows the average experimental results in terms of cutting and thrust forces, chip contact length, chip thickness and shear angle.

Table 2. Experimental results

\begin{tabular}{lccc}
\hline Test case & 1 & 2 & 3 \\
\hline Cutting force $\mathrm{F}_{\mathrm{c}}[\mathrm{N}]$ & 745 & 715 & 1027 \\
\hline Thrust force $\mathrm{F}_{\mathrm{t}}[\mathrm{N}]$ & 600 & 522 & 749 \\
\hline Chip thickness $[\mathrm{mm}]$ & 0.288 & 0.220 & 0.355 \\
\hline Shear angle $[\mathrm{deg}]$ & 19.0 & 24.4 & 23.0 \\
\hline Temperature $\left[{ }^{\circ} \mathrm{C}\right]$ & 542 & 567 & 596 \\
\hline
\end{tabular}

\subsection{Numerical procedure}

In the present study the FEM commercial software "DEFORM-2D" was used to simulate orthogonal cutting. The reference cutting condition used was identified in test case 1 of Table 1 and Table 2.

Workpiece and tool sizes in simulation model were set large enough so that the predicted results were not sensitive to the boundary conditions. Figure 3 shows the FE model with the thermocouple socket position. 


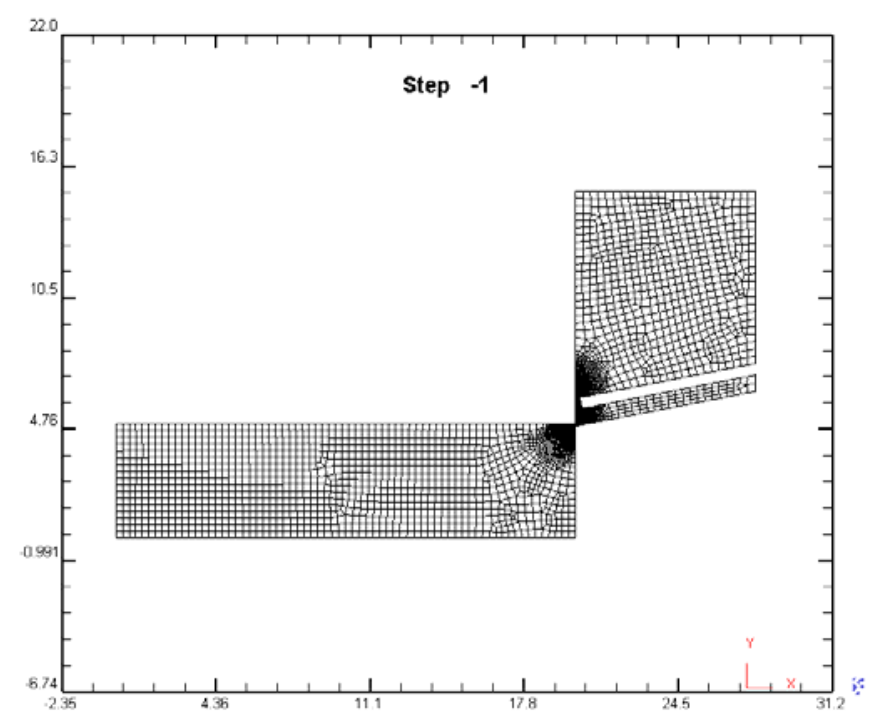

Fig. 3. FE model

An Updated-Lagrangian simulation was executed utilizing a well-known power law for the workpiece material. In particular, in this first case the employed model was the one proposed by Oxley [1], in which the effective flow stress is computed as an exponential function of the effective strain $\varepsilon$ (Eq. 1):

$\sigma=\sigma_{1} \varepsilon^{n_{1}}$

being $\sigma_{l}$ the strength coefficient and $n_{1}$ the strainhardening exponent. Both $\sigma_{l}$ and $n_{1}$ vary with velocity-modified temperature $T_{\bmod }$, which couples

the effects of strain rate $\varepsilon$ and the temperature $T_{1}$. The concept of velocity-modified temperature was proposed by MacGregor and Fisher [9] and is defined as:

$T_{\text {mod }}=T_{1}\left(1-v \log \frac{\dot{\varepsilon}}{\varepsilon_{0}}\right)$

where $v$ and $\varepsilon_{0}$ are constants that depend on the workpiece material and are readily available [1]. The relationship between $T_{\text {mod }}$ and $\sigma_{1}$ and the relationship between $T_{\text {mod }}$ and $n_{1}$ have been experimentally established for carbon steels using high speed compression tests [1].

The aim of this step was to find the friction model and the friction value in order to obtain a numerical shear angle as nearest as possible to the experimental one. In fact, an important assumption is here done, according with previous results [5]: the chip-tool geometry is not relevantly dependent on the material law and thermal distribution. On the contrary, it's strongly related to friction coefficient. Thus, in this phase no thermal aspects were considered and the $h$ value was set equal to zero. In particular the constant shear friction model with a coefficient equal to 0.98 permitted to obtain the minimum shear angle error.

Subsequently, an Eulerian analysis was run taking into account the Lagrangian step outputs. It's worth noticing, in fact, that both the deformed mesh and the velocity distributions were assumed as input for the Eulerian analysis. In this case the workpiece material behaviour was described by means of a simple law (Eq. 3) taking into account strain-rate and temperature:

$\sigma=C \cdot \dot{\varepsilon}^{m} \cdot T^{-\gamma}$

where $\mathrm{C}, \mathrm{m}$ and $\gamma$ are constants.

These constants were found utilizing an inverse procedure based on the optimization algorithm of Newton-Raphson. In particular, the three unknown parameters were determined minimizing the objective function $\mathrm{E}$, representing the difference between the experimental and corresponding computed cutting and thrust forces and temperature:

$$
E=\sqrt{\left(\left(F_{c}{ }^{\text {num }}-F_{c}{ }^{\exp }\right)^{2}+\left(F_{t}^{\text {num }}-F_{t}{ }^{\exp }\right)^{2}+\left(T^{\text {num }}-T^{\exp }\right)^{2}\right)}
$$

where the numerical values derive from the Eulerian finite element simulation.

Of course, Eq. 3 introduces a strong simplification in the analysis, partially justified by the fact that a sensitivity analysis shown that the strain influence is lower than the others. In particular, in Eulerian frame all the data are not related with strain.

Finally, it was possible to identify the following material law:

$\sigma=970 \cdot \dot{\varepsilon}^{0.006} \cdot T^{-0.0225}$

The application of this simple power law in Eulerian step of the turning process provided the results reported in Table 3 which also reports the prediction accuracy.

Table 3. Results for $\mathrm{V}_{\mathrm{c}}=100 \mathrm{~m} / \mathrm{min}$ and a f $=0.1 \mathrm{~mm} / \mathrm{rev}$

\begin{tabular}{cccccc}
\hline $\mathrm{F}_{\mathrm{c}}[\mathrm{N}]$ & $\mathrm{eF}_{\mathrm{c}} \%$ & $\mathrm{~F}_{\mathrm{t}}[\mathrm{N}]$ & $\mathrm{eF}_{\mathrm{t}} \%$ & $\mathrm{~T}$ & $\mathrm{eT} \%$ \\
\hline 745.2 & 0.03 & 600.2 & 0.03 & 542.6 & 0.11 \\
\hline
\end{tabular}

Subsequently, the law (Eq. 5) was used to predict the cutting and thrust forces such as the temperature in two new cases, with different cutting conditions. Also in these cases the procedure was the previously illustrated one. A Lagrangian simulation was 
performed, utilizing the Oxley's law to describe the AISI 1045 behaviour. The coefficient was determined in order to approach the experimental geometry. Also in these cases, the constant shear model and the friction coefficient equal to 0.98 allowed to minimize the errors. The relative errors for the shear angle were about 5\% and $9 \%$ respectively. Table 4 reports the predicted variable at the end of the Eulerian simulation for a cutting speed of $150 \mathrm{~m} / \mathrm{min}$ and feed equal to $0.1 \mathrm{~mm} / \mathrm{rev}$.

Table 4. Results for $\mathrm{V}_{\mathrm{c}}=150 \mathrm{~m} / \mathrm{min}$ and a $\mathrm{f}=0.1 \mathrm{~mm} / \mathrm{rev}$

\begin{tabular}{cccccc}
\hline $\mathrm{F}_{\mathrm{c}}[\mathrm{N}]$ & $\mathrm{eF}_{\mathrm{c}} \%$ & $\mathrm{~F}_{\mathrm{t}}[\mathrm{N}]$ & $\mathrm{eF}_{\mathrm{t}} \%$ & $\mathrm{~T}$ & $\mathrm{eT} \%$ \\
\hline 694.4 & -2.9 & 570.9 & 9.4 & 515.9 & -9.0
\end{tabular}

Forces, temperature and relative errors for a cutting speed of $100 \mathrm{~m} / \mathrm{min}$ and a feed rate of $0.15 \mathrm{~mm} / \mathrm{rev}$ are summarized in Table 5.

Table 5. Results for $\mathrm{V}_{\mathrm{c}}=100 \mathrm{~m} / \mathrm{min}$ and a $\mathrm{f}=0.15 \mathrm{~mm} / \mathrm{rev}$

\begin{tabular}{cccccc}
$\mathrm{F}_{\mathrm{c}}[\mathrm{N}]$ & $\mathrm{eF}_{\mathrm{c}} \%$ & $\mathrm{~F}_{\mathrm{t}}[\mathrm{N}]$ & $\mathrm{eF}_{\mathrm{t}} \%$ & $\mathrm{~T}$ & $\mathrm{eT} \%$ \\
\hline 1045.8 & 1.8 & 821.7 & 9.7 & 575.7 & -3.4 \\
\hline
\end{tabular}

\section{SOME CONSIDERATIONS}

The preliminary proposed procedure provided satisfactory results, as it appears analyzing the data reported in the Tables 3-5. In fact, the average error is less than $10 \%$ and the researchers involved in this field surely agree to consider this discrepancy absolutely acceptable. Of course the calibration and validation procedures are not so robust at this state but the actual aim of this work is to propose a breaking procedure which starts from a different point of view respect to the traditional approaches.

Its main point of strength is the possibility to simulate the process in Eulerian environment, without knowing a priori the material flow rule. The latter can be directly derived by using simple steps if some mechanical and thermal data are available.

In the opinion of the authors this way could constitute a point of discontinuity with the past since material is characterised in its real processing conditions thus it is intrinsically more robust and physically consistent. Temperature, strain and, mainly, strain rate are of the same order of the process ones, at difference of any other characterisation test.

On the other hand, it is clear that substantial improvements will be necessary in terms of robustness and completeness.

\section{CONCLUSIONS}

The preliminary results of a study concerning material modelling through simple machining tests were presented. Nevertheless the strong simplification and the rough calibration and validation approach, the performance of the proposed procedure was verified comparing the numerical and experimental data.

In the future, the methodology has to be surely refined supplying a powerful procedure able to allow the simple calculation of the material constitutive low just measuring few experimental data.

\section{ACKNOWLEDGEMENTS}

The authors gratefully thank prof. Luca Settineri of ISTECCNR for his support in developing the experiments.

\section{REFERENCES}

1. P.L.-B. Oxley, Mechanics of Machining - An Analytical Approach to Assessing Machinability, Ellis Horwood Limited, London (1989).

2. G.-R. Johnson, W.-H. Cook, A Constitutive Model and Data for Metals Subjected to Large Strains, High Strain Rates and High Temperatures, Proceedings of the Int. Symposium on Ballistics, Netherlands, (1983) 541-547.

3. P. Sartkulvanich, F. Koppa, T. Altan, Determination of Flow Stress for Metal Cutting Simulation - a Progress Report, Journal of Materials Processing Technology, 146, (2004) 61-71.

4. T. Shirakashi, K. Maekawa, E. Usui, Flow stress of low carbon steel at high temperature and strain rate (Parts III), Bulletin of the Japan Society of Precision Engineering, 16, (1983) 161-172.

5. L. Filice, F. Micari, S. Rizzuti, D. Umbrello, Dependance of Machining Simulation Effectiveness on Material and Friction Modelling. That's Why Industrial Application of Machining Simulation is still so far, Proceedings of the $10^{\text {th }}$ Int. Workshop on Modelling of Machining Operations, Reggio Calabria, (2007) 181-187.

6. T.H.C. Childs, Friction Modelling in Metal Cutting, Wear, 260 (3), (2006) 310-318.

7. J. Hua, R. Shivpuri, Prediction of Chip Morphology and Segmentation during the Machining of Titanium Alloys, Journal of Materials Processing Technology, 150 (1-2), (2004) 124-133.

8. N. Ahmed, A.V. Mitrofanov, V.I. Babitsky, V.V. Silberschmidt, 3D Finite Element Analysis of Ultrasonically Assisted Turning, Computational Materials Science, 39 (1), (2007) 149-154.

9. C.-W. Mac Gregor, J.-C. Fisher, 'A Velocity-Modified Temperature for the Plastic Flow of Metals', ASME J. Appl. Mech., 13, (1946) 211-218. 